\title{
Effect of Target Removal on Goldfish Optic Nerve Regeneration: Analysis of Fast Axonally Transported Proteins
}

\author{
G. W. Perry, D. W. Burmeister, ${ }^{a}$ and Bernice Grafstein \\ Department of Physiology, Cornell University Medical College, New York, New York 10021
}

How is axonal transport in regenerating neurons affected by contact with their synaptic target? We investigated whether removing the target (homotopic) lobe of the goldfish optic tectum altered the incorporation of ${ }^{3} \mathrm{H}$-proline into fast axonally transported proteins in the regenerating optic nerve. Regeneration was induced either by an optic tract lesion (to reveal the changes in the original axon segment that remained connected to the cell body) or by an optic nerve lesion (to reveal the changes in the newly formed axon segment). Of 26 proteins analyzed by 2-dimensional gel electrophoresis and fluorography, all but one showed increased labeling as a result of tectal lobe ablation. By $2 \mathrm{~d}$ after the lesion, significantly increased labeling of some proteins was seen with a 6-hr labeling interval, but not with a 24-hr labeling interval. This is probably indicative of an increased velocity of transport, which may have been a nonspecific consequence of the surgery. Otherwise, tectal lobe removal had relatively little effect until 3 weeks, when there was a transitory increase in labeling of transported proteins in the new axon segments of the tectum-ablated animals. Beginning at 5 weeks, tectal lobe ablation caused considerably higher labeling of many of the proteins in the original axon segments. Because this was seen with both 6-hr and 24-hr labeling intervals, it is probably indicative of increased protein synthesis. The increased synthesis lasted until at least 12 weeks, though some proteins were beginning to show a diminished effect at this time. In the late stages of regeneration (8-12 weeks), there was also increased labeling of proteins in the new axon segments as a result of the absence of the target tectal lobe. This included a disproportionately large increase in the relative contribution of cytoskeletal proteins and of protein 4, which is the goldfish equivalent of the growth-associated protein GAP-43 (neuromodulin). We conclude that, after the regenerating axons begin to innervate the tectum, the expression of most of the proteins in fast axonal transport is down-regulated by interaction between the axons and their target. However, the changes in expression may be preceded by a modulation of the turnover and/or deposition of proteins in the newly formed axon segment.

Received Mar. 27, 1990; revised June 18, 1990; accepted June 25, 1990.

This work was supported by U.S. Public Health Service Grants R01-NS09015, R01-NS14967, and T32-NS07138 to B.G. and R01-EY06449 to G.W.P.

Correspondence should he addressed to Dr. Gary W. Perry, Center for Complex Systems, Florida Atlantic University, P.O. Box 3091, Boca Raton, FL 334310991.

aPresent address: Department of Pharmacology, Columbia University College of Physicians and Surgeons, New York, NY 10032.

Copyright (C) 1990 Society for Neuroscience $0270-6474 / 90 / 103439-10 \$ 03.00 / 0$
Regeneration in goldfish optic axons involves a massive increase in axonal transport of proteins (Grafstein and Murray, 1969; McQuarrie and Grafstein, 1982). In a previous study, we found that, following intraocular injection of ${ }^{3} \mathrm{H}$-proline, all of the fast axonally transported optic nerve proteins in a molecular weight range of about $20-200 \mathrm{kDa}$ and a $\mathrm{pI}$ range of $4.5-7.0$ demonstrable by 2-dimensional gel electrophoresis (2D-PAGE) and fluorography showed increased labeling during regeneration (Perry et al., 1987). This was attributable primarily to increased synthesis of the transported proteins in the retinal ganglion cells.

In addition to increased protein synthesis, the goldfish retinal ganglion cells show other dramatic metabolic and morphological alterations in response to axotomy (Murray and Grafstein, 1969; Grafstein, 1986). The cell-body changes are eventually reversed if the regenerating optic axons succeed in reinnervating the optic tectum. The factors that influence the recovery of the cell body are not yet all known, but it has been clearly demonstrated that the reaction to axotomy is prolonged if the target (contralateral) lobe of the tectum has been removed (Burmeister and Grafstein, 1985). For example, under normal conditions of regeneration at $20^{\circ} \mathrm{C}$, the retinal ganglion cells reach their maximum size at 2-3 weeks after the lesion, when the regenerating axons begin to invade the tectum, and approach their normal size by 10-12 weeks. In the absence of the target lobe of the tectum, however, the cells are still close to their peak size at 10-12 weeks and remain significantly enlarged even at 26 weeks (D. W. Burmeister and B. Grafstein, unpublished observations).

The present study was undertaken in order to determine how individual fast-transported proteins are affected during the prolongation of the cell-body reaction. We found that virtually all the proteins we examined are regulated by the tectum in the late stages of regeneration. This includes the important "growthassociated protein" (GAP) that is the goldfish counterpart of mammalian GAP-43 (Benowitz and Routtenberg, 1987; Skene, 1989), also designated "neuromodulin" (Liu and Storm, 1989), which was thought by previous workers to be uninfluenced by the presence of the tectum (Benowitz et al., 1983).

\section{Materials and Methods}

Animals. Goldfish (Carassius auratus), 9-11 cm in body length and 30$40 \mathrm{gm}$ body weight, were obtained from Ozark Fisheries, Stoutland, MO. They were maintained in 10-gallon aquaria at room temperature (approximately $21^{\circ} \mathrm{C}$ ) with a 14:10-hr light: dark lighting cycle.

Surgical procedures. In goldfish anesthetized in ice, the optic axons emanating from the right eye were lesioned either by crushing the right optic nerve with jeweller's forceps 1-2 $\mathrm{mm}$ behind the eye or by cutting the left optic tract intracranially (Perry et al., 1987). In half the fish in each group, the left lobe of the optic tectum (to which the right eye projects as a result of axonal decussation at the chiasma, and hence is referred to as the "homotopic" lobe with respect to the regenerating 


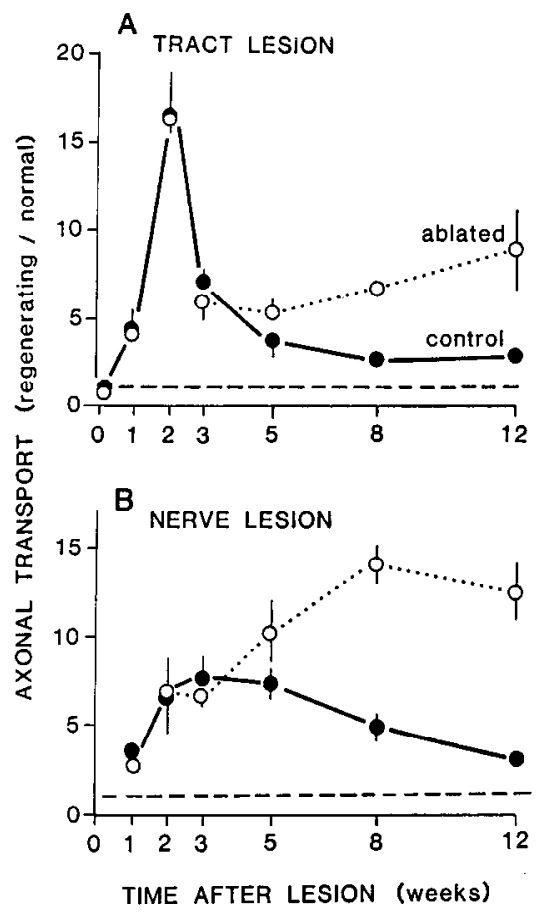

Figure 1. Labeling of total transported protein in optic nerve sample in $(A)$ tract-lesion experiments and $(B)$ nerve-lesion experiments, measured $24 \mathrm{hr}$ after intraocular injection of ${ }^{3} \mathrm{H}$-proline. Open circles, animals with the homotopic lobe of the optic tectum ablated; solid circles. animals with the optic tectum intact. Measurements of total transported trichloracetic acid (TCA)-precipitable radioactivity were expressed in $\mathrm{dpm} / \mu \mathrm{Ci}$ injected per nerve sample, and the values for the regenerating nerves were divided by the mean value for normal nerves (from shamoperated fish). The broken line indicates a regenerating/normal value of 1 . Each data point is the mean \pm SEM of 3-7 samples, each containing 1 or 2 nerves.

axons) was removed by gentle aspiration, leaving the subtectal structures and the right ("heterotopic") lobe of the tectum intact. In the rest of the lesioned fish, which served as regenerating controls, a skull flap only was cut and replaced with no further surgery. The results obtained from these control fish, together with the results obtained from a group of sham-operated fish, have been described in detail in a previous study (Perry et al., 1987).

Analysis of fast axonally transported proteins. At various times after surgery, the right eye of each fish was injected with ${ }^{3} \mathrm{H}$-proline, and 6 or $24 \mathrm{hr}$ later, each labeled optic nerve, together with its contiguous optic tract, was removed. Labeled fast-transported proteins in the optic nerve samples were quantitatively analyzed by $2 D-P A G E$ as described previously (Perry et al., 1987). Briefly, the nerve samples were solubilized in an SDS solution, and, after an aliquot was removed for determination of total protein labeling, the remaining sample was analyzed by 2 D-PAGE, in which the nerve proteins were separated first according to their isoelectric point in a $\mathrm{pH}$ gradient ranging from 4.5 to 7.0 , then according to their molecular weight in a $10 \%$ polyacrylamide gel that separated proteins ranging from 20 to $200 \mathrm{kDa}$. We have found that the majority of axonally transported optic nerve proteins are contained within these limits (Perry et al., 1987). The gels were fluorographically enhanced (Bonner and Laskey, 1974), dried, and used to expose preflashed Kodak XAR x-ray film in order to visualize the labeled proteins. The fluorographs were used as templates for excising the areas from the gel corresponding to individual fast-transported proteins, and the radioactivity in each protein was determined by liquid scintillation spectrometry (Perry and Wilson, 1981). To reduce the variance of the values, for example, due to differences in incorporation of radioactivity from one fish to another, the raw disintegrations per minute (dpm) value for each spot was divided by the total dpm recovered from all the spots on the gel and multiplied by the mean total dpm of the protein spots from all the gels in any group (see Perry et al., 1987, for details). Thus, the final values were expressed in dpm for each spot, representing a function of the absolute level of labeling for that spot at various times. [This is different in principle from a normalization procedure used by some other workers (e.g., Skene and Willard, 1981; Szaro et al., 1985), in which changes in individual proteins were detectable only if they differed from the mean changes in the population of proteins.]

To analyze the effects of tectal ablation, we have determined whether the arithmetic difference between the mean values for each prolein in the tectum-ablated and tectum-intact animals was statistically significant at each time point. This criterion was established by Student's $t$ test or Satterthwaite's (1946) moditied Student's $t$ test (see Figs. 3-7). In order to illustrate the relative effects on the various proteins in the population, we have plotted the ratio of the mean values at each time point (see Fig. 10).

\section{Results}

\section{Changes in total labeling of fast-transported optic nerve} protein

As we have previously emphasized (Perry et al., 1987), it is important to distinguish between the changes in labeling occurring in the optic nerve following an optic tract lesion and those after an optic nerve lesion. With a tract lesion, the optic nerve sample contains the original axon segments that remain connected to their cell bodies, and hence the proteins that are labeled following intraocular injection of ${ }^{3} \mathrm{H}$-proline consist principally of transported proteins passing through to the growing portion of the axons. With a nerve lesion, the nerve sample contains newly regenerated optic axon segments, and hence the labeled material includes proteins that are being laid down during reconstitution of these axon segments.

Following an optic tract lesion (Fig. 1A), the total labeling of fast-transported protein (resulting from a 24-hr labeling period with ${ }^{3} \mathrm{H}$-proline) reached a peak of nearly 20 times the normal at about 2 weeks and then declined, regardless of whether or not the homotopic tectal lobe was present. By 5 weeks, however, the effect of tectal ablation started to become evident. If the homotopic tectal lobe was present, the labeling continued to decline, reaching nearly normal levels by 12 weeks, whereas with the homotopic lobe ablated, not only was there no decline, but a small continuous increase in labeling occurred between 5 and 12 weeks. Similar results were obtained with a 6-hr incorporation period for ${ }^{3} \mathrm{H}$-proline (data not shown).

After an optic nerve lesion, the protein labeling in the optic nerve sample increased to about 7 times the normal at 2 weeks (Fig. 1B). In the animals with the tectum intact, the level of labeling remained relatively constant between 2 and 5 weeks and then declined slowly. In the animals with the homotopic tectal lobe ablated, however, the labeling continued to increase after 3 weeks, so that at 8-12 weeks there was a very large discrepancy between the results obtained under the 2 different conditions.

\section{Changes in individual transported proteins}

We have previously described the regeneration-associated changes in ${ }^{3} \mathrm{H}$-proline incorporation into about 25 individual fast-transported proteins, as revealed by fluorographic analysis of 2D-PAGE (Perry et al., 1987). Most of these proteins were seen to be labeled with both 6-and 24-hr incorporation periods. All the transported proteins labeled in the regenerating nerves were also found to be labeled in undamaged optic nerves. Also, all of them showed increased incorporation of the label in both the original and the new axon segments. However, the time course and magnitude of the changes were different for different proteins. These differences were the basis for separating the proteins into 5 different classes (Perry et al., 1987). This clas- 

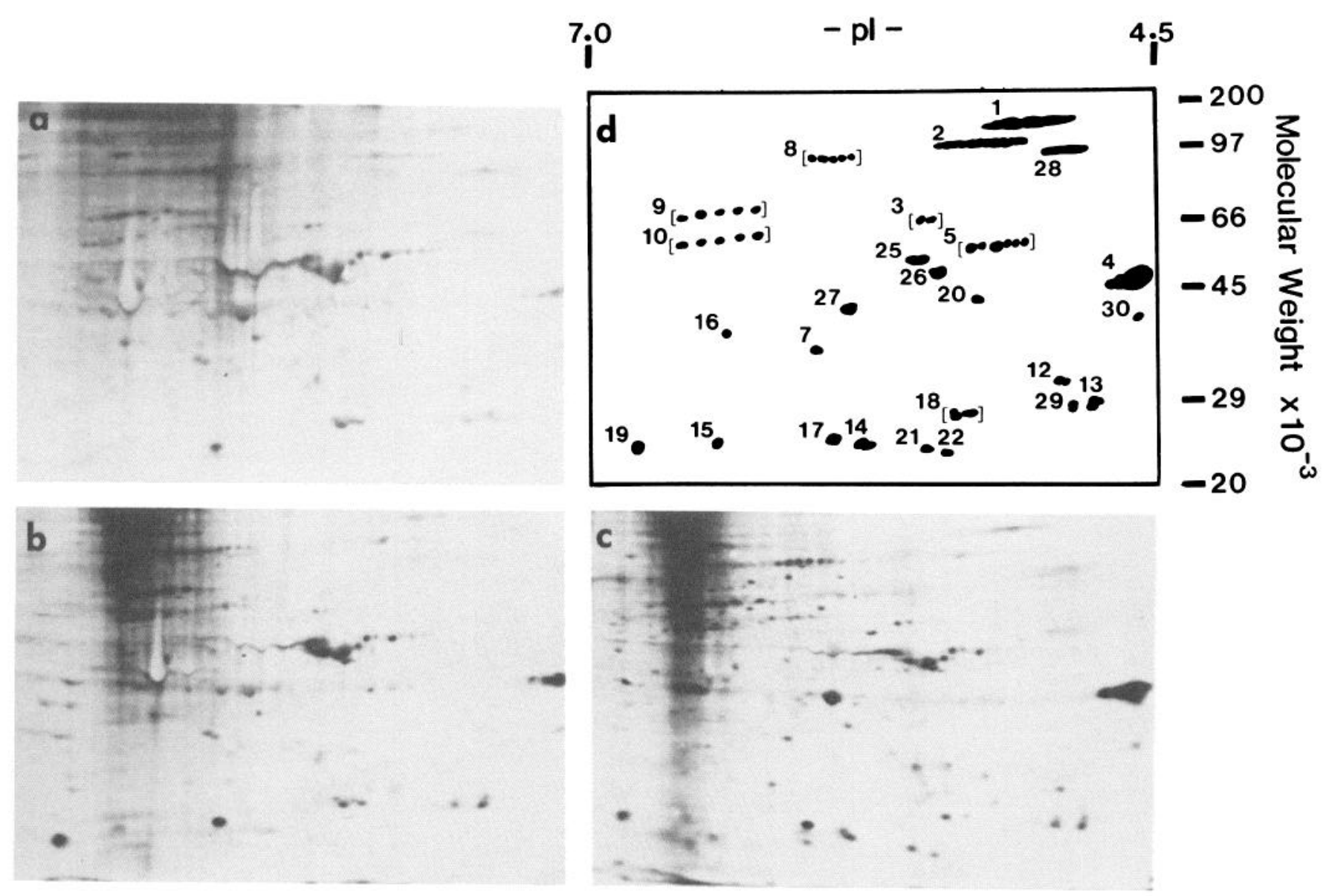

Figure 2. Fluorographic patterns of 2D-PAGE gels, showing labeling of fast-transport proteins in optic nerve at $24 \mathrm{hr}$ after intraocular injection of ${ }^{3} \mathrm{H}$-proline. Proteins were separated in ranges of pI 4.5-7.0 and molecular weight 20,000-200,000. Molecular weight standards (Sigma) were: 20,000 (myoglobin), 29,000 (carbonic anhydrase), 45,000 (ovalbumin), 66,000 (bovine serum albumin), 97,000 (phosphorylase B), and 200,000 (myosin). $a$, Pattern of fast-transport proteins collected in normal (sham-operated) optic nerves. This fluorograph was developed after a 3-month exposure. $b$ and $c$, Pattern of fast-transport proteins in an optic nerve regenerating in the presence $(b)$ or absence $(c)$ of the homotopic lobe of the tectum, 12 weeks after optic tract lesion. Fluorographs were exposed for 4 months $(b)$ and 6 weeks $(c)$. $d$, Map of fast-transport proteins seen in normal and regenerating optic nerves. The map is representative of the fluorographic patterns obtained in this study. Arbitrary numbers have been assigned to identify these proteins (Perry et al., 1987).

sification, which may have some value for recognizing separate groups of coregulated proteins (Grafstein et al., 1987), has been retained for the present study.

Figure 2 shows examples of the fluorographic patterns of the fast-transported proteins present in the normal optic nerve (Fig. $2 a$ ) and in regenerating optic nerve in the presence (Fig. $2 b$ ) or absence (Fig. $2 c$ ) of their homotopic tectum at $24 \mathrm{hr}$ after an intraocular injection of ${ }^{3} \mathrm{H}$-proline. These patterns demonstrate that the population of labeled fast-transported proteins in the optic nerves is the same regardless of whether they were regenerating in the presence or absence of their homotopic tectum. However, as regeneration proceeded, there was almost invariably more labeling of individual transported proteins in the tectum-ablated fish than in the tectum-intact fish (Figs. 3-7). In the original segments, significant differences in labeling for a number of proteins $(8,9,10,15,17,21,22$, and 25 , i.e., including nearly all the proteins in Class B) began to appear at 5 weeks. By 8 weeks, almost all the proteins examined showed a statistically significant increase in labeling in either the original or the new axon segments, or both. At 12 weeks, labeling was almost invariably still significantly higher in tectum-ablated fish than during normal regeneration, with a number of proteins continuing to increase their labeling (e.g., Class B, Fig. 4), whereas some remained constant (Class C, Fig. 5), and others already showed a downturn (e.g., some members of Class A, Fig. 3). Only 1 relatively weakly labeled protein (12), showed almost no ablation-induced changes that were statistically significant at the $5 \%$ level of confidence; nevertheless, its time course of labeling was consistent with that of some other Class A proteins (Fig. 3). In most cases, the magnitude of the change in the new segments, especially at 12 weeks, was larger than the corresponding change in the original segments. Especially prominent effects of tectal ablation were observed in the new axon segments for proteins 2, 4, 25 ( $\alpha$-tubulin), and 26 ( $\beta$-tubulin). A comparison of the contributions of various individual proteins to the total picture of protein labeling showed that, with the target lobe of the optic tectum ablated, protein 4 came to play an increasingly dominant role in the new axon segments (Fig. $8 A, B$ ): at 12 weeks, it accounted for nearly $40 \%$ of the labeling in these segments (excluding cytoskeletal elements). The original axon segments showed a less abnormal picture. Although there was more labeling overall (Fig. 1A), there was only a small change 
Figure 3. Quantitative analysis of 24-hr labeling of Class $A$ individual transported proteins. The proteins are arranged in classes according to the temporal sequence of changes seen in the original axon segments during regeneration (Perry et al., 1987). The numbering of each protein is as shown in Figure $2 d$. For each protein, the radioactivity in the original axon segments (upper panel) and new axon segments (lower panel) is shown at various times (given in weeks) after the lesion. Ordinate values represent the radioactivity in each spot in $\mathrm{dpm} \times 10^{-3}$ (adjusted as described in Materials and Methods). Solid circles and solid line, fish with homotopic tectal lobe ablated. Solid squares and broken line, fish with tectum intact. (These data are as presented in Perry et al., 1987.) Solid triangle, sham-operated fish. Each point indicates the mean \pm SEM of measurements from 3-6 gels. Arrowheads indicate that the difference between 2 values at that time point is statistically significant at the $5 \%$ level or better by Student's $t$ test for unpaired samples (Satterthwaite, 1946).

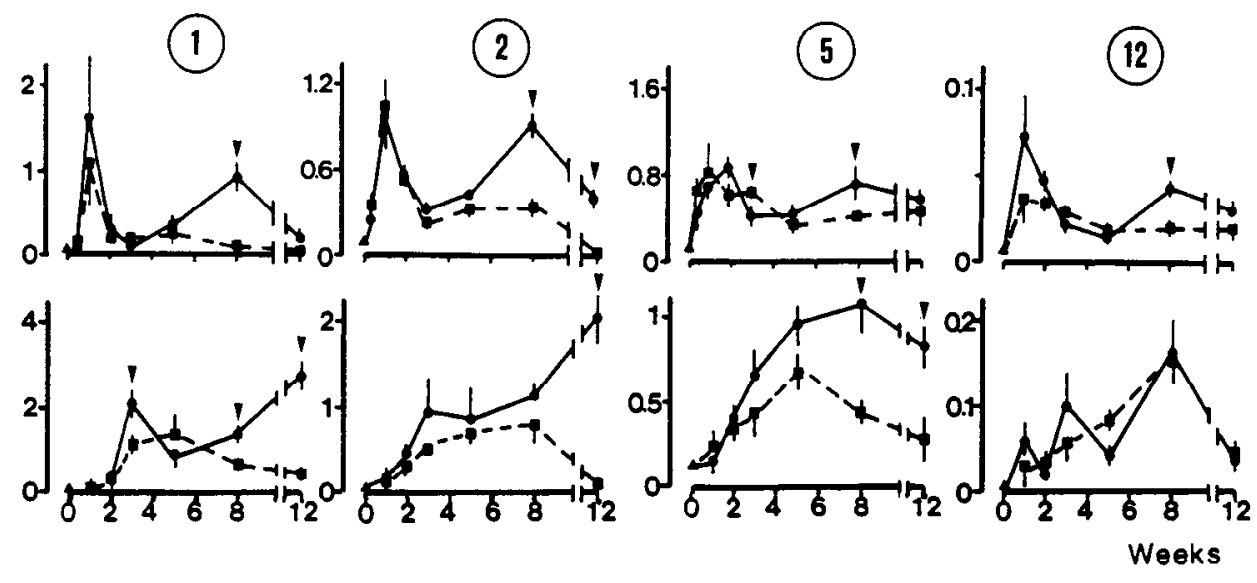

CLASS A
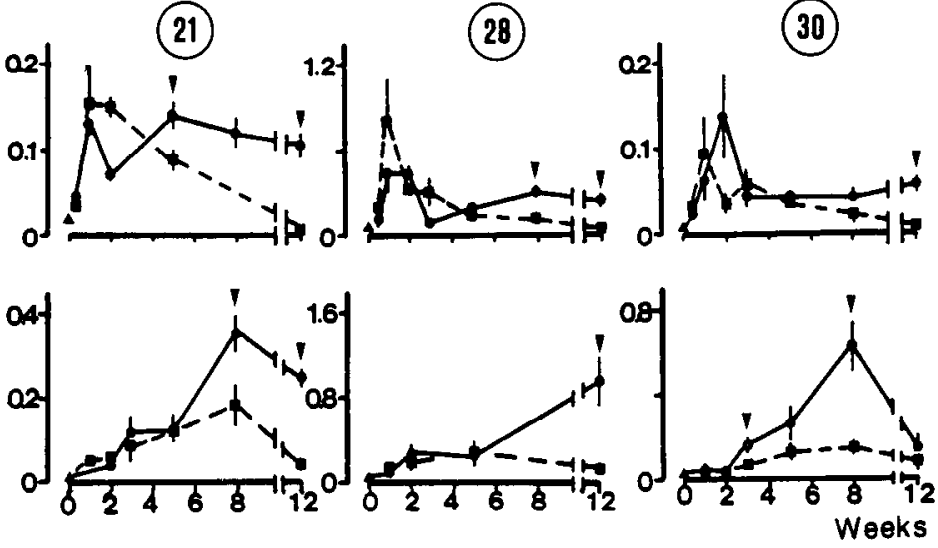

in the relative contributions of the individual proteins. Thus, at 12 weeks, the distribution of radioactivity among the various proteins was close to that seen in normal nerve, regardless of whether the tectum was present or not (Fig. 8C,D).

In contrast to the large changes seen during the later stages of regeneration, the differences between the tectum-intact and tectum-ablated animals were much less evident during the first 3 weeks. For example, for those proteins that showed a sharp peak in labeling within the first 3 weeks, the same peak was observed in the absence of the homotopic tectal lobe. This was particularly clearly seen in the case of the Class B proteins, with both a tract lesion and a nerve lesion (Fig. 4), but was also evident in other protein classes, as well. Thus, the decline from the early peak is not due to a regulatory effect of contact with the tectum, though it apparently occurs at about the time that the contact would be made.

A less detailed survey done with a 6-hr labeling period in the intact axon segments likewise showed that tectal ablation resulted in generally higher levels of labeling in almost all the proteins examined (Fig. 9), but there were certain interesting differences from the 24-hr labeling patterns. One was that significant effects of tectal ablation were already evident for a number of proteins $(4,8,17$, and 27$)$ by $2 \mathrm{~d}$ after the lesion/ablation. In fact, protein 4 showed a significant increase at all the time points examined with the 6-hr labeling interval. Also, the cytoskeletal proteins ( $25, \alpha$-tubulin; $26, \beta$-tubulin; 27 , actin) showed a significant increase in labeling at many time points. However, as with the 24-hr labeling interval, it was only from 5 weeks onward that the consequences of tectal ablation were significant for the majority of the proteins.

To get an overview of the effects specifically associated with removal of the tectum, we determined for each protein the labeling ratio between the tectum-ablated and tectum-intact animals (Fig. 10). This enabled us to perceive trends in the data that affected many of the proteins simultaneously, even when the individual differences failed to reach a statistically significant level. It became evident, for example, that at some time points, most of the values in the tectum-ablated animals were less than the corresponding values for normal regeneration, though the reductions were statistically significant only in isolated instanccs. Thus, the following sequence emerged: Beginning at $2 \mathrm{~d}$, tectal ablation caused increased labeling in the original segments at $6 \mathrm{hr}$, whereas the 24-hr labeling was somewhat reduced below the levels seen during normal regeneration. At 3 weeks, the 24 $\mathrm{hr}$ labeling of the original segments was again reduced as a result of tectal ablation, whereas the labeling in the new segments was increased, even reaching a statistically significant level for a few proteins $(1,6,7,15,17,18$, and 30$)$. This increase was only a transitory one, however. By 5 weeks, the elevated labeling in the new segments had disappeared (except for protein 4), whereas the original segments showed increased labeling with both 6-hr and 24-hr incorporation periods. By 8 weeks, the labeling in both the new and the original segments was almost consistently increased and remained so through 12 weeks. In the original segments, however, there were some proteins $(1,4,5,7$, $16,17,18,25,26$, and 27$)$ that showed a smaller ratio at 12 


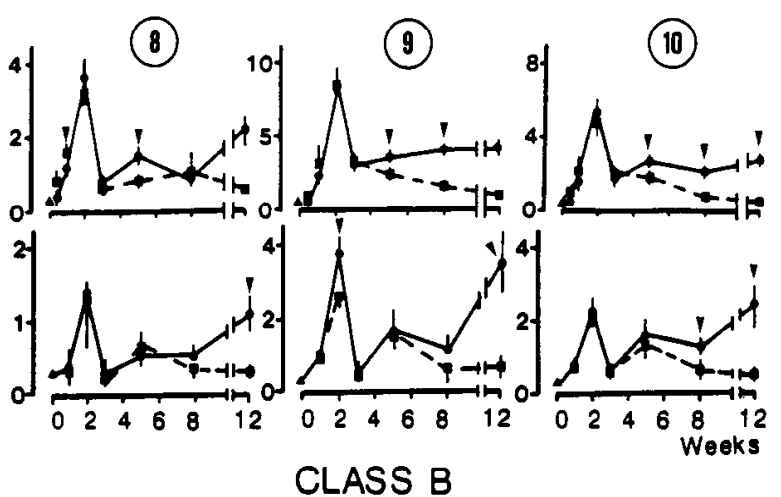

(15)

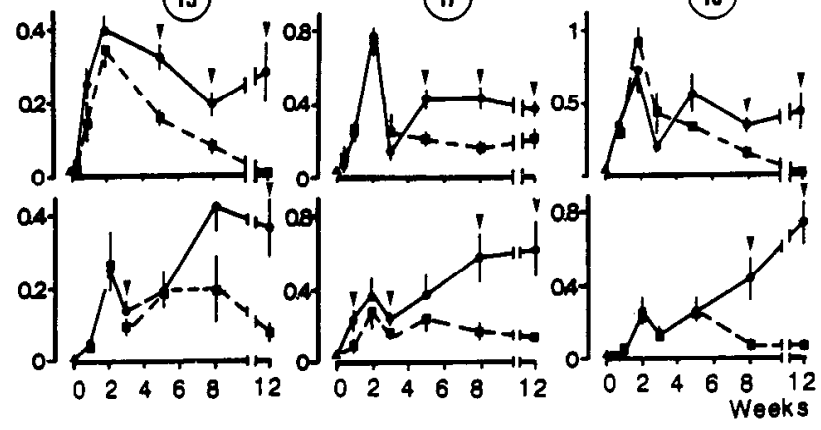

Figure 4. Quantitative analysis of 24-hr labeling of Class B individual transported proteins (numbered as shown in Fig. $2 d$ ). See Figure 3 caption for details.

(7)

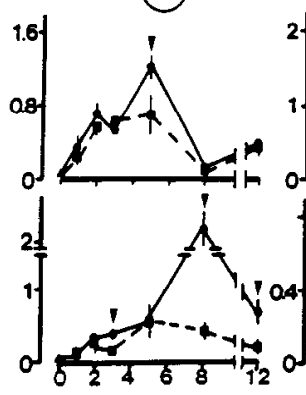

CLASS D
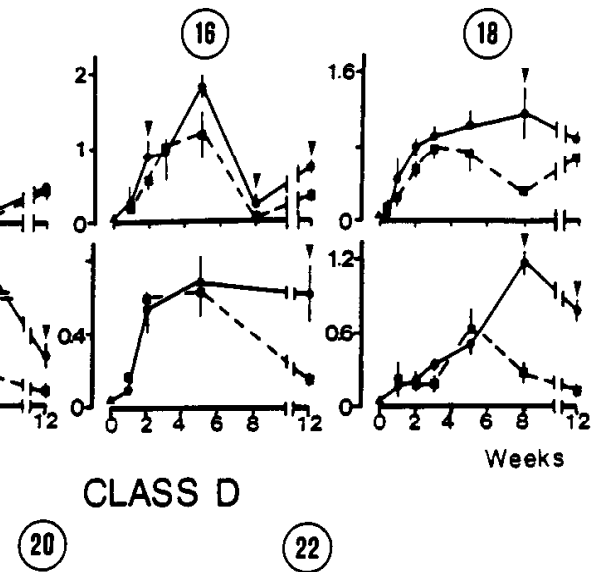

(22)

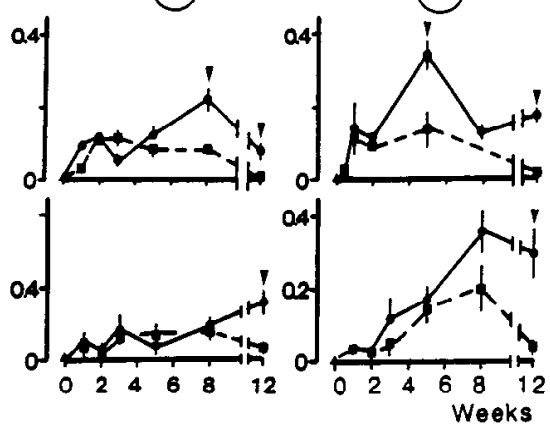

Figure 5. Quantitative analysis of 24-hr labeling of Class C individual transported proteins (numbered as shown in Fig. $2 d$ ). See Figure 3 caption for details.

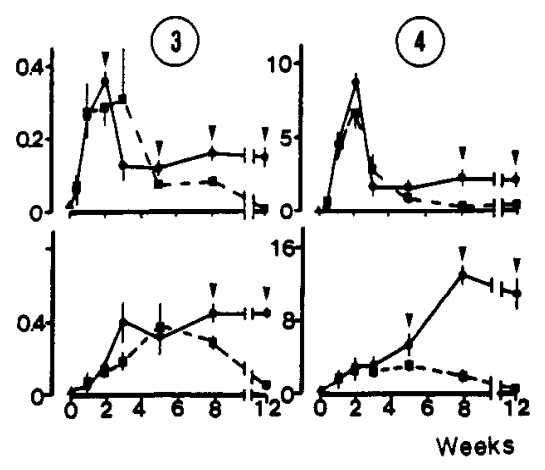

CLASS C

(13)

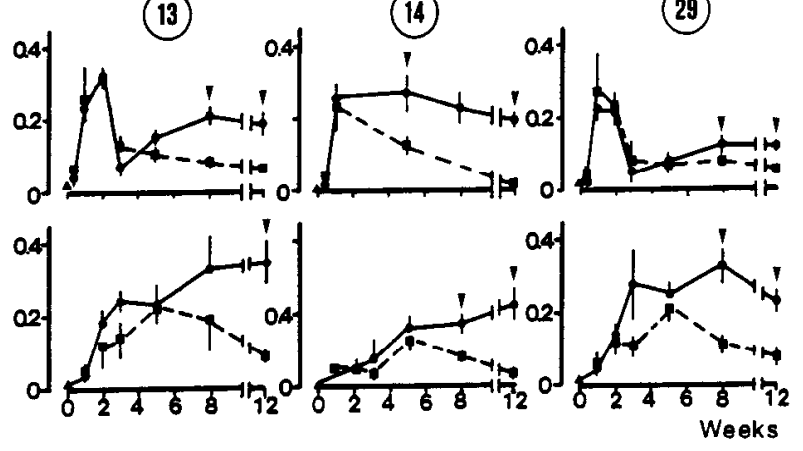

Figure 6. Quantitative analysis of 24-hr labeling of Class D individual transported proteins (numbered as shown in Fig. $2 d$ ). See Figure 3 caption for details.

weeks than at 8 weeks, which suggests that some of the effects of tectal ablation were beginning to diminish at this time.

\section{Discussion}

Effect of tectal ablation on optic axon regeneration

In the normal animal, most of the optic axons terminate in the homotopic lobe of the optic tectum, that is, contralateral to their eye of origin. A small proportion project to the contralateral diencephalon and pretectum, and an even smaller proportion project ipsilaterally. After ablation of the homotopic tectal lobe, some of the regenerating axons invade the remaining tectal lobe,

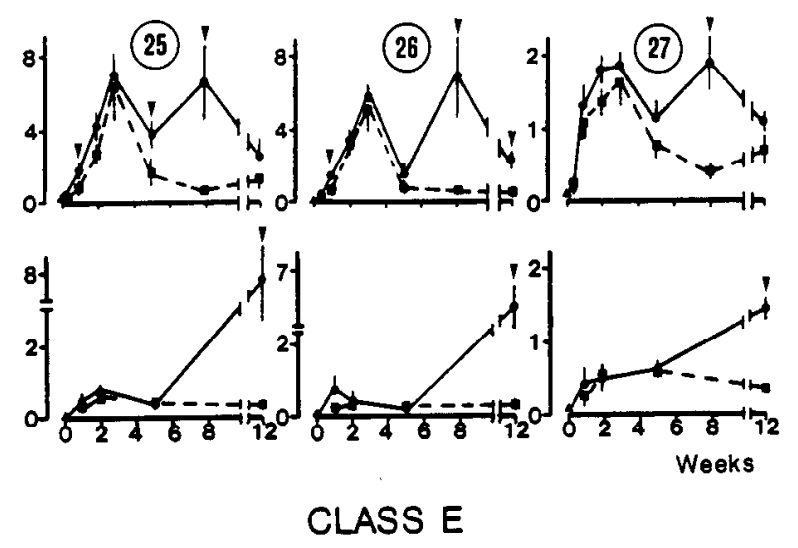

Figure 7. Quantitative analysis of 24-hr labeling of Class E individual transported proteins (numbered as shown in Fig. 2d). See Figure 3 caption for details. 

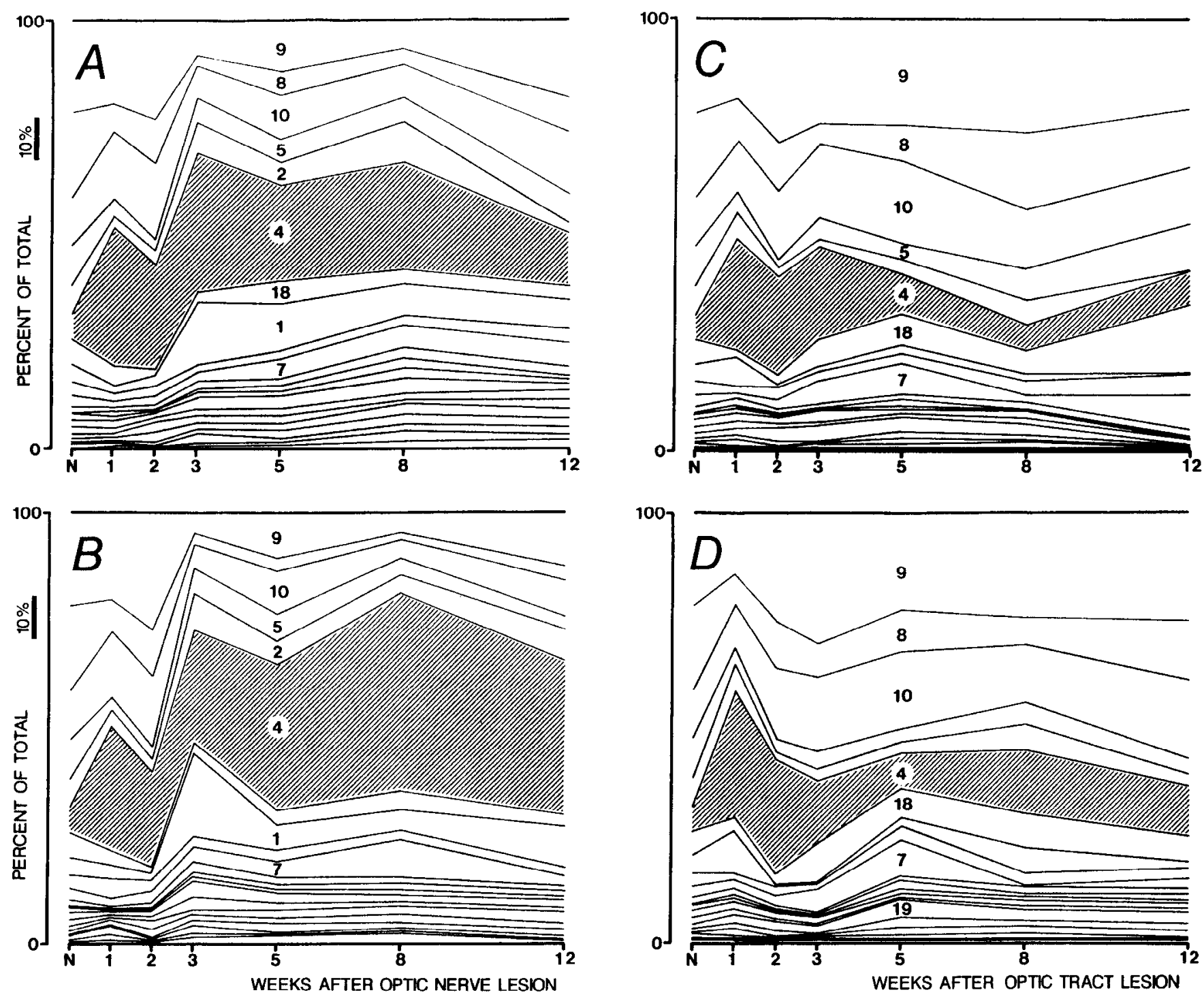

Figure 8. Labeling of individual proteins in new axon segments during regeneration following optic nerve lesion $(A, B)$ and in original axon segments following optic tract lesion $(C, D)$. $A$ and $C$, Tectum intact; $B$ and $D$, Homotopic lobe of tectum ablated. The contribution of each protein is shown as a percentage of the total summed label in the analyzed proteins (24-hr labeling). The proteins have been arranged in the order of their relative contributions to the labeling in nerves from sham-operated animals, with the protein showing the largest normal value at the top of the graph. Cytoskeletal proteins (proteins 25-27) have been omitted because data were not available for all time points. (Panel $A$ of this figure has been reproduced from Perry et al., 1987, with permission.)

some grow into the diencephalon and midbrain on the homotopic side, and a few grow back through the tegmentum for several $\mathrm{mm}$ beyond their usual termination level (Lo and Levine, 1980; Burmeister and Grafstein, 1985). Even the axons that are routed into the remaining tectal lobe do not begin to invade the tectal tissue until about 4 weeks, which is 2 weeks later than normal, and do not cover the tectum completely until 6-8 weeks, compared to about 4 weeks in the normal. Thus, in many of the axons, the period of elongation lasts longer than usual, and the onset of synaptogenesis is thereby delayed (Reich et al., 1990). Many of the regenerated projections are abnormally located (Lo and Levine, 1980); however, most ganglion cells apparently have branches that cross into the remaining tectal lobe between 4 and 10 weeks after tectal lobe ablation (D. W. Burmeister and B. Grafstein, unpublished observations). The refinement of the retinotectal projection, in which incorrectly targeted axons are eliminated (Schmidt, 1982; Meyer, 1983), probably takes longer at these abnormal sites (Burmeister and Grafstein, 1985). Recovery takes even longer in ganglion cells that can never find an appropriate target (Burmeister and DunnMeynell, 1987).

\section{Changes in protein labeling induced by tectal removal}

All of the proteins that we studied, with perhaps a single exception, showed increased labeling as a result of tectal ablation. Increased labeling has usually been attributed to increased protein synthesis and equated with increased gerie expression (e.g., Skene and Willard, 1981; Yoon et al., 1986). It does not necessarily indicate an increased amount of protein present, because the increased synthesis might, for example, be balanced by increased degradation. However, in some cases (e.g., protein 4), increased labeling during regeneration was accompanied by in- 


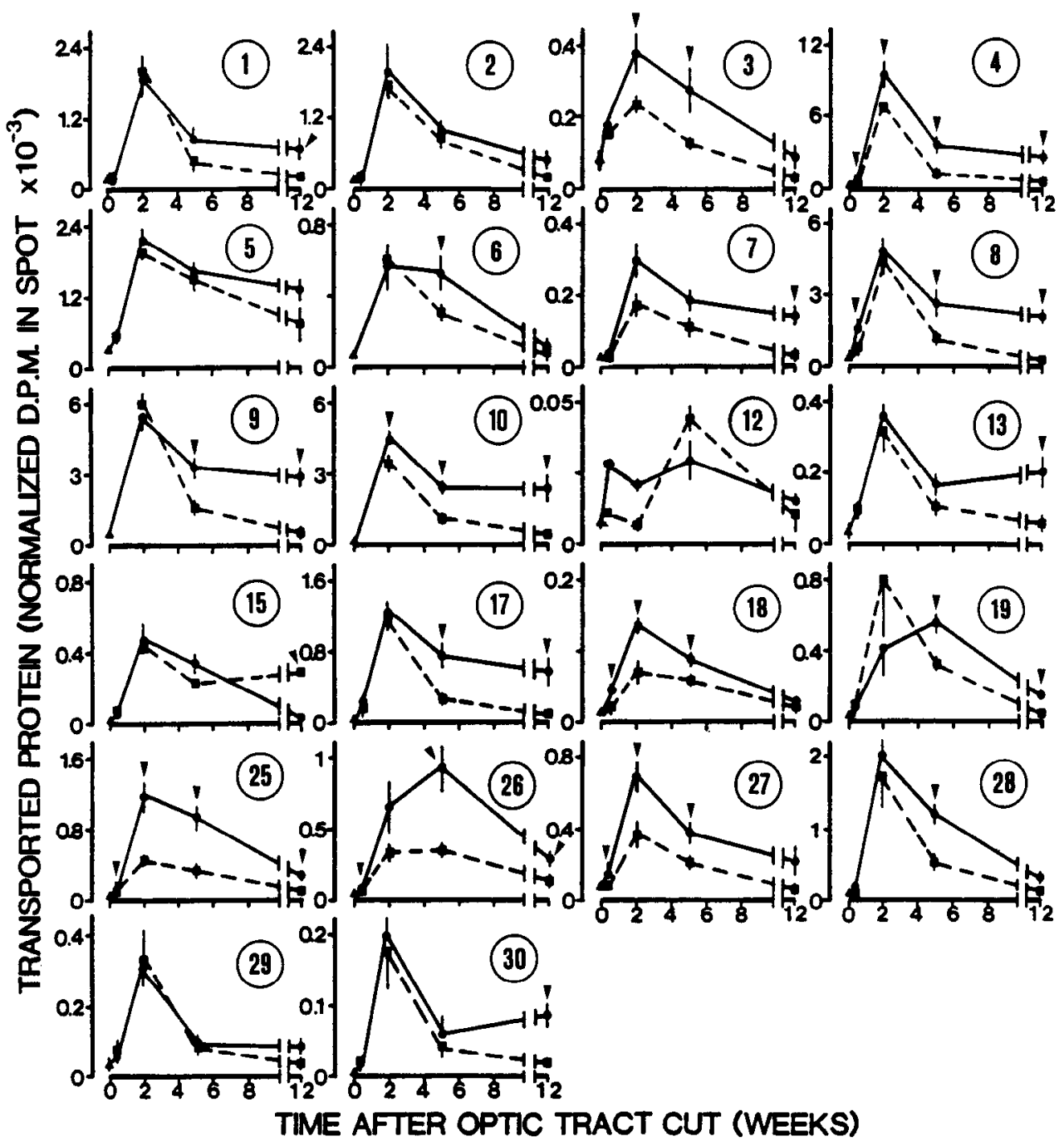

Figure 9. Quantitative analysis of 6-hr labeling of individual transported proteins in the original axon segments following optic-tract lesion. All the protein spots analyzed are shown in Figure $2 \mathrm{~d}$. The labeled fast-transport proteins are essentially the same after $6 \mathrm{hr}$ and $24 \mathrm{hr}$ of labeling (see Perry et al., 1987). Circles and solid line, fish with homotopic tectal lobe ablated. Solid squares and broken line, fish with tectum intact (as in Perry et al., 1987). Solid triangle, control (sham-operated) fish. Each point represents the mean \pm SEM of 3-6 determinations. Arrowheads indicate statistically significant differences as described in Figures 3-7. creased staining of the protein spot on gels of regenerating nerves (Perry et al., 1985), indicating that the abundance of this protein was indeed increased. Alterations in the labeling of a particular protein may also be due to a number of other factors, such as changes in the dynamics of axonal transport that might alter the proportion of protein in transit versus protein deposited in the nerve (Perry et al., 1987).

\section{Changes prior to the normal time of contact with the tectum}

Some consequences of removal of the tectum were already seen at $2 \mathrm{~d}$ after the lesion, when ablation produced a significant selective increase in the labeling of some proteins, including protein 4 and the cytoskeletal proteins $(25,26$, and 27$)$. Nevertheless, at this early time, this increase was only seen with the 6-hr incorporation period, whereas the values for 24-hr incorporation were, if anything, somewhat reduced. This pattern is difficult to reconcile with an increase in expression, but may be indicative of the faster appearance of the proteins in the nerve, resulting from an increase in transport velocity or an earlier release from the cell body (Perry et al., 1987). Conceivably, this might be a specific consequence of removal of the tectum, operating via a diffusible neurotrophic factor released from the tectum (Schwartz et al., 1982; Giulian, 1984b). However, ac- celerated emergence of transported proteins has been detected in the goldfish optic nerve very soon after surgery, even in shamoperated animals (McQuarrie and Grafstein, 1982; J. R. Sparrow and B. Grafstein, unpublished observations). The effect is greater with increasing damage to the CNS (McQuarrie and Grafstein, 1982), as will have occurred in the present study when, in addition to a nerve or tract lesion, the tectum was ablated. The same phenomenon may also be responsible for changes that have been seen in both retinas when only 1 optic nerve has been damaged (Kohsaka et al., 1981), which suggests that it may be a systemic effect.

At 1 week of regeneration, the tectum-ablated fish showed a significant increase in the labeling of $\alpha$ - and $\beta$-tubulin (25 and 26 ) in the intact portion of the axons (Fig. 10, $24 \mathrm{~h}$ tract lesion). This change was no longer evident, however, at 2-3 weeks.

Except for these limited changes, tectal removal had relatively little effect during the early stages of regeneration. With the tectum intact, many proteins showed a large increase in labeling that peaked at 1-2 weeks and declined sharply at about the time that the axons would normally have made their first contact with the optic tectum. This increase, however, was unaffected in magnitude or time course by ablation of the tectum and hence cannot be ascribed solely to loss of contact with the tectum. It 

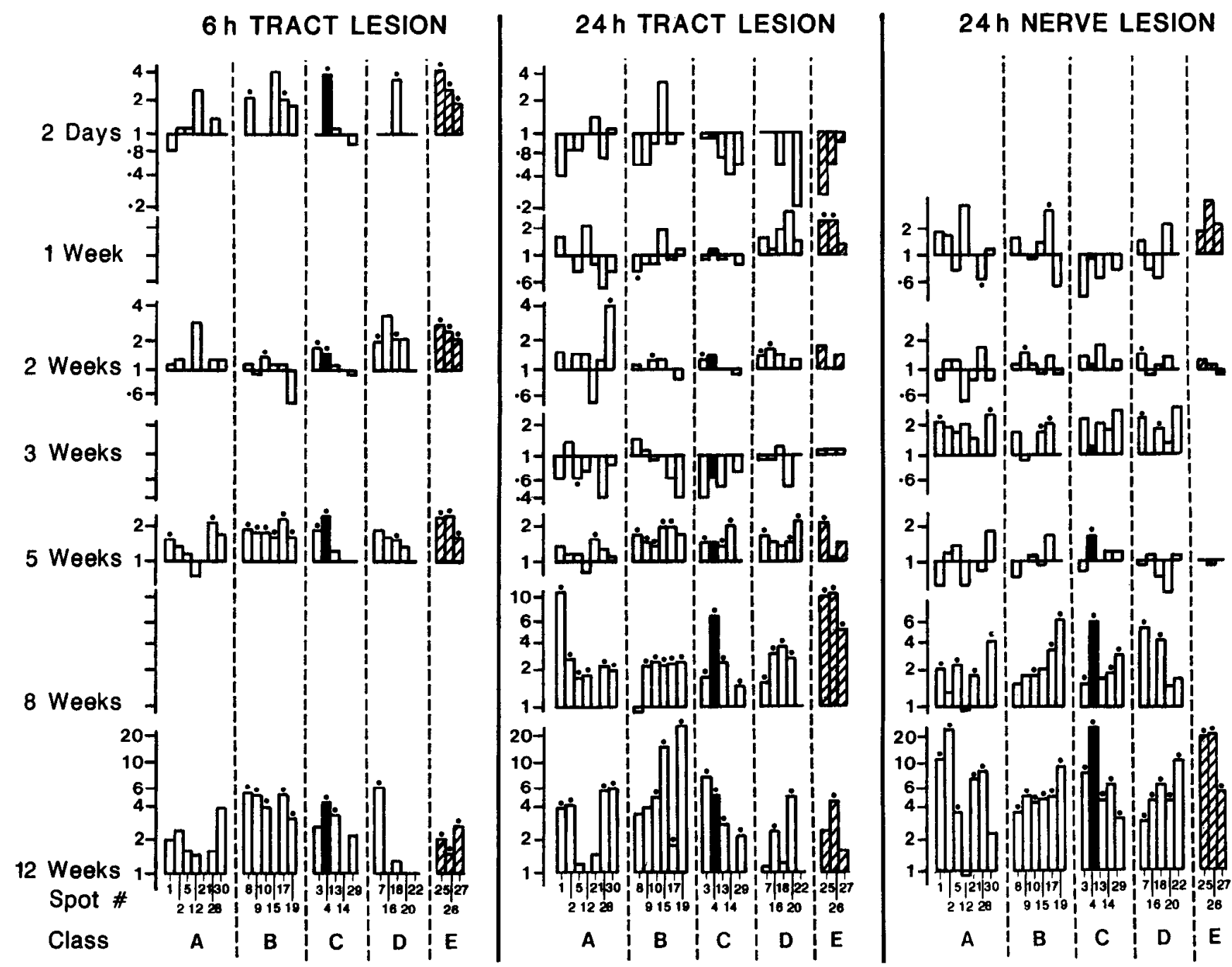

Figure 10. Ratios of values from tectum-ablated and tectum-intact fish for individual proteins (arranged according to classes as in Perry et al., 1987). Note the logarithmic scales of the ordinate. Solid bars indicate values for protein 4 (homologue of GAP43/neuromodulin). Hatched bars indicate values for the cytoskeletal proteins $\alpha$ - and $\beta$-tubulin (proteins 25 and 26) and actin (protein 27). Solid circles indicate that the difference between the 2 values is statistically significant, as described in Figures 3-8.

is possible that the increase represents an initial self-limiting reaction to injury or a response to the trophic effect of nonneuronal cells in the optic nerve. Protein synthesis in these cells rises to a maximum at about 2 weeks of regeneration (Giulian et al., 1980; Maxwell and Elam, 1980; G. W. Perry, unpublished observations) and could include an increased production of neurotrophic factors to be taken up by the growing axons (Neuman et al., 1987). Alternatively, neurotrophic effects may ensue from surface interactions upon contact with the glial cells (Liuzzi and Lasek, 1987).

\section{Changes after normal time of contact with the tectum}

We did not find any proteins in which changes usually seen during regeneration failed to be initiated in the absence of the tectum. Thus, there was no evidence of any changes in expression of axonally transported proteins that might be specifically associated with contact between the regenerating axons and their target. This is consistent with our previous finding that there were no proteins in which increased labeling was first seen upon contact with the tectum (Perry et al., 1987). The discrepancy between this finding and the results reported by previous workers (Giulian, 1984a; Yoon et al., 1986) is probably due to the fact that we were measuring absolute levels of protein labeling, whereas most others (Skene and Willard, 1981; Benowitz et al., 1983; Szaro et al., 1985; Yoon et al., 1986) have been concerned with differences relative to the mean level in the entire protein population; also, we have been careful to distinguish between events in the original and new axon segments. Nevertheless, it is possible that some proteins outside the range of our gels, for example, the $300-\mathrm{kDa}$ "tectally regulated" protein described by Giulian (1984a), may have properties different from those that we observed.

Increased expression (i.e., synthesis) of any protein would have been recognizable in the present study from an increase in labeling in the original axon segments with both 6-hr and 24$\mathrm{hr}$ labeling intervals. This was consistently seen only after 5 weeks. Among the proteins showing a statistically significant response to tectal ablation at this time were virtually all of the Class B proteins. During normal regeneration, the proteins in this class show an unusually high level of labeling in the new axon segments at 2 weeks (Perry et al., 1987), which suggests that they might be proteins that are preferentially delivered to the elongating portion of the axons. Two proteins in Class B (9 and 10) are now known to be phosphorylated (Larrivee and 
Grafstein, 1987) and may function as microtubule-associated proteins (Larrivee, 1989) of the chartin type (Aletta and Greene, 1987).

Even prior to the changes in expression, however, many proteins showed a transitory increase in labeling in the new axon segments. This increased accumulation of transported material in the new segments occurred at 3 weeks, precisely the time that the regenerating axons would normally be entering the homotopic tectum and beginning synapse formation. This change is difficult to attribute to increased production or transport of axonal constituents, because there was no concomitant change in the original axon segments. It is more likely, therefore, to be due to altered turnover or deposition of these proteins in the newly generated portion of the axons.

At 5 weeks, when increased expression of some proteins did occur as a result of tectal ablation, there was virtually no effect on the labeling of the new axon segments, suggesting that the changes in expression were just sufficient to compensate for the changes in turnover. Increased labeling of the new segments did, however, appear at 8 weeks, and in most cases, the discrepancy between the tectum-ablated and tectum-intact animals was further increased at 12 weeks (Fig. 10). The exceptionally high labeling of the cytoskeletal proteins (particularly $\alpha$-tubulin and $\beta$-tubulin) suggests that the cytoskeletal dynamics in the axons regenerating in the absence of the tectum were still very abnormal at this time. This may reflect the continued elongation of a substantial proportion of the axonal population.

A striking abnormality in the tectum-ablated animals at 12 weeks was the relatively large contribution to the total labeling that was attributable to protein 4 . It represented about $40 \%$ of the total label, compared to an initial value of less than $5 \%$ in the undamaged nerve and less than $15 \%$ at the same time during normal regeneration. This phosphoprotein is the goldfish homologue of GAP-43 (Skene and Willard, 1981; Benowitz and Lewis, 1983; Benowitz and Routtenberg, 1987) or neuromodulin (Liu and Storm, 1989). It is believed to play an important role in neurite growth and regeneration, as well as in other manifestations of neuronal plasticity, such as long-term potentiation in the mammalian brain (Skene, 1989). It is a prominent constituent of developing and regenerating axons and is enriched in growth cones. Its enhanced expression may be a necessary condition for regeneration, but does not ensure that regeneration will occur (Doster et al., 1988; Perng and Perry, 1988). Previous workers (Benowitz et al., 1983; Yoon et al., 1986) have found, as here, that labeling of this protein "is greatly increased at early stages of regeneration and then subside(s) . . . whether the tectum is present or not" (Benowitz et al., 1983). The inference that the expression of this protein is not regulated by the tectum applies, however, to only the early stages of regeneration; from the present study, it is clear that once tectal contact is made, the expression of this protein does come under tectal control to a significant degree. Evidence of target regulation of GAP-43 has previously been obtained in mammalian sensory axons in vivo (Bisby, 1987) and in vitro (Baiser and Fishman, 1987).

It does not seem to be adequate, however, to characterize the effect of target removal as "prolonging" the changes that occur during regeneration (Bisby, 1982; Mizrachi et al., 1984; Burmeister and Grafstein, 1985). While it is certainly correct that after removal of the tectum the expression of most of the proteins we examined did remain above normal for a much longer time, this expression was not just maintained at a constant level. In many cases, it increased to levels equal to, or significantly exceeding, the maximum seen prior to the usual time of contact with the tectum. Thus, in the absence of the tectum, the regeneration-associated changes in expression do not only fail to regress, but continue to evolve. It is possible that reversal of these changes becomes more difficult as the pattern of protein expression becomes increasingly abnormal.

It is interesting that, for some proteins, their increased expression was clearly preceded by an increased labeling confined to the new axon segments. Therefore, alterations in the deposition or turnover of transported materials in the new axon segment may be an important intermediary event in tectal regulation of the cell body. For example, when the regenerating axons begin to penetrate the tectal terrain, their elongation rate decreases (Grafstein, 1986), which would probably entail a change in axonal transport dynamics. Another possibility is that, upon entering the tectum, the growing axons may encounter a change in the composition of the extracellular matrix or the availability of trophic factors, leading to local changes in the turnover of axonal constituents or in the activity of some regulatory enzymes. Such posttranslational mechanisms might then provide a trigger for changes in protein expression, presumably conveyed to the cell body by retrograde axonal transport (Forman, 1983).

\section{References}

Aletta JM, Greene LA (1987) Sequential phosphorylation of chartin microtubule-associated proteins is regulated by the presence of microtubules. J Cell Biol 105:277-290.

Baizer L, Fishman MC (1987) Recognition of specific targets by cultured dorsal root ganglion neurons. J Neurosci 7:2305-2311.

Benowitz LI, Lewis ER (1983) Increased transport of 44,000-49,000 dalton acidic proteins during regeneration of the goldfish optic nerve: a 2-dimensional analysis. J Neurosci 3:2153-2163.

Benowitz LI, Routtenberg A (1987) A membrane phosphoprotein associated with neural development, axonal regeneration, phospholipid metabolism and synaptic plasticity. Trends Neurosci 10:527532.

Benowitz LI, Yoon MG, Lewis ER (1983) Transported proteins in the regenerating optic nerve: regulation by interactions with the optic tectum. Science 222:185-188.

Bisby MA (1982) Prolonged alteration in composition of fast transported protein in axons prevented from regenerating after injury. $J$ Neurobiol 13:377-381.

Bisby MA (1987) Dependence of GAP43 (B50, F1) transport on axonal regeneration in rat dorsal root ganglion neurons. Brain Res 458:157161.

Bonner WM, Laskey RA (1974) A film detection method for tritiumlabelled proteins and nucleic acids in polyacrylamide gels. Eur $\mathbf{J}$ Biochem 46:83-88.

Burmeister DW, Dunn-Meynell AA (1987) Recovery of regenerating goldfish retinal ganglion cells is slowed in the absence of the topographically correct synaptic target. Brain Res 423:56-62.

Burmeister DW, Grafstein B (1985) Removal of the optic tectum prolongs the cell body reaction to axotomy in goldfish retinal ganglion cells. Brain Res 327:45-51.

Doster SK, Lozano AM, Willard M, Aguayo AJ (1988) Axonal transport of GAP-43 in injured and regenerating retinal ganglion cell axons of adult rats. Soc Neurosci Abstr 14:802.

Forman DS (1983) Axonal transport and nerve regeneration: a review. In: Spinal cord reconstruction (Kao CC, Bunge RP, Reier PJ, eds), pp 75-85. New York: Raven.

Giulian D (1984a) Target regulation of protein biosynthesis in retinal ganglion cells during regeneration of the goldfish visual system. Brain Res 296:198-201.

Giulian D (1984b) Peptides from the regenerating central nervous system of goldfish stimulate glia. Proc Natl Acad Sci USA 81:35673571 .

Giulian D, Des Ruisseaux H, Cowburn D (1980) Biosynthesis and intra-axonal transport of proteins during neuronal regeneration. J Biol Chem 255:6494-6501.

Grafstein B (1986) The retina as a regenerating organ. In: The retina: a model for cell biology studies (Adler R, Farber D, eds), pp 275335. New York: Academic. 
Grafstein B, Murray M (1969) Transport of protein in goldfish optic nerve during regeneration. Exp Neurol 25:494-508.

Grafstein B, Burmeister DW, McGuinness CM, Perry GW, Sparrow JR (1987) Role of fast axonal transport in regeneration of goldfish optic axons. Prog Brain Res 71:113-120.

Kohsaka S, Schwartz M, Agranoff BW (1981) Increased activity of ornithine decarboxylase in goldfish following optic nerve crush. Dev Brain Res 1:391-401.

Larrivee D (1989) Altered microtubule associated protein (MAP) phosphorylation during optic nerve regeneration. Soc Neurosci Abstr 15:879.

Larrivee DC, Grafstein B (1987) Phosphorylation of proteins in normal and regenerating goldfish optic nerve. J Neurochem 49:17471757.

Liu Y, Storm DR (1989) Dephosphorylation of neuromodulin by calcineurin. J Biol Chem 264:12800-12804.

Liuzzi FJ, Lasek RJ (1987) Astrocytes block axonal regeneration in mammals by activating the physiological stop pathway. Science 237 : 642-645.

Lo RYS, Levine R (1980) Time course and pattern of optic fiber regeneration following tectal lobe removal in the goldfish. $J$ Comp Neurol 191:295-314.

Maxwell JK, Elam JS (1980) Amino acid incorporation into proteins of degenerating and regenerating goldfish optic tracts. Exp Neurol 67: $118-130$.

McQuarrie IG, Grafstein B (1982) Protein synthesis and fast axonal transport in regenerating goldfish retinal ganglion cells. Brain Res 235: 213-223.

Meyer RL (1983) Tetrodotoxin inhibits the formation of refined retinotopography in goldfish. Dev Brain Res 6:293-298.

Mizrachi Y, Neumanm D, Sharma S, Schwartz M (1984) Targetdependent and independent stages in regeneration. Brain Kes 322: $115-118$.

Murray M, Grafstein B (1969) Changes in the morphology and amino acid incorporation of regenerating goldfish optic neurons. Exp Neurol 23:544-560.
Ncumann R, Korshing S, Bandtlow C, Thoenen H (1987) Changes of nerve growth factor synthesis in nonneuronal cells in response to sciatic nerve transection. J Cell Biol 104:1623-1631.

Perng G-S, Perry GW (1988) Changes in specific fast axonally transported proteins in crushed frog and rat optic nerve. Soc Neurosci Abstr 14:804.

Perry GW, Wilson DL (1981) Protein synthesis and axonal transport during nerve regeneration. J Neurochem 37:1203-1217.

Perry GW, Burmeister DW, Grafstein B (1985) Changes in protein content of goldfish optic nerve during degeneration and regeneration following nerve crush. J Neurochem 44:1142-1151.

Perry GW, Burmeister DW, Grafstein B (1987) Fast axonally transported proteins in regenerating goldfish optic axons. J Neurosci 7: 792-806.

Reich JB, Burmeister DW, Schmidt JT, Grafstcin B (1990) Effect of conditioning lesions on regeneration of goldfish optic axons: time course of the cell body reaction to axotomy. Brain Res 515:256-260.

Satterthwaite FE (1946) An approximate distribution of estimates of variance components. Biometr Bull 2:110-114.

Schmidt JT (1982) The formation of retinotectal projections. Trends Neurosci 5:111-115.

Schwartz M, Mizrachi Y, Eshhar N (1982) Factor(s) from goldfish brain induce neuritic outgrowth from explanted regenerating retinas. Dev Brain Res 3:29-35.

Skene JHP (1989) Axonal growth-associated proteins. Annu Rev Neurosci 12:127-156.

Skene JHP, Willard M (1981) Changes in axonally transported proteins during regeneration in toad retinal ganglion cells. J Cell Biol 89: 86-95.

Szaro BG, Loh YP, Hunt RK (1985) Specific changes in axonally transported proteins during regeneration of the frog (Xenopus laevis) optic nerve. J Neurosci 5:192-208.

Yoon MG, Benowitz LI, Baker FA (1986) The optic tectum regulates the transport of specific proteins in regenerating optic fibers of goldfish. Brain Res 382:339-351. 